\title{
Increased organohalogen diversity after disinfection of water from a prescribed burned watershed
}

Christopher I. Olivares ${ }^{\ddagger \ddagger}$, Habibullah Uzun ${ }^{\S}$, Cagri Utku Erdem ${ }^{\ddagger}$, Wenbo Zhang", Carl

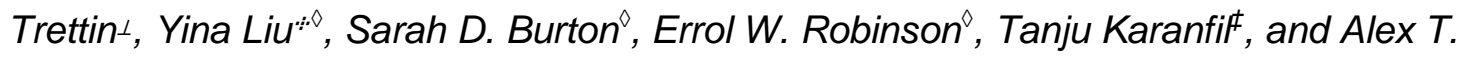
Chow $^{\ddagger} / \|^{*}$

${ }^{\dagger}$ Civil \& Environmental Engineering, University of California, Berkeley, Berkeley, CA

FDepartment of Environmental Engineering \& Earth Science, Clemson University, SC

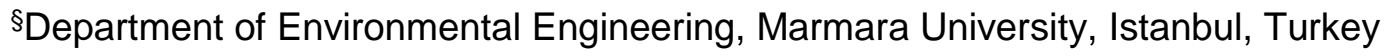

"Baruch Institute of Coastal Ecology \& Forest Science, Clemson University, SC

${ }^{\perp}$ Center for Forested Wetland Research, USDA Forest Service, 3734 Highway 402, Cordesville, SC, 29434, USA

Department of Oceanography, Texas A\&M University, College Station, TX ${ }^{\circledR}$ Environmental Molecular Sciences Laboratory, Pacific Northwest National Lab, WA

*Corresponding author: Alex T. Chow (chow@clemson.edu)

Contents: 7 figures 


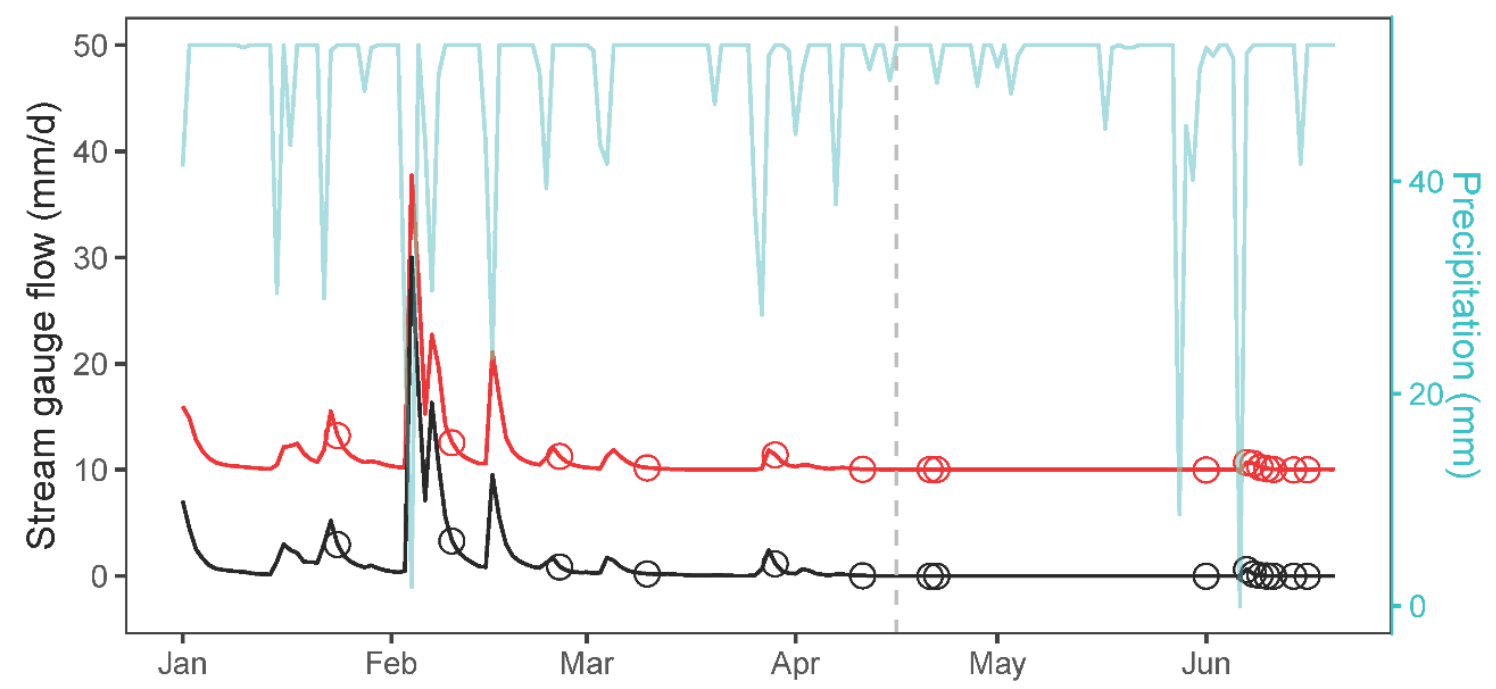

Figure S1. Stream gauge flow for the first half of 2016 in the burned (red) and unburned (black) watersheds in the Santee Experimental Forest, South Carolina, USA. The burned watershed flow is offset by $10 \mathrm{~mm} / \mathrm{d}$ from the unburned for easier visualization. Grab sample timepoints are indicated by open circles. The dotted gray line shows the date of the prescribed burn (April 16). The secondary y-axis shows precipitation at the nearest USGS meteorological station to the study site, Turkey Creek. Flow and precipitation retrieved from the Santee Experimental Forest Portal Data.

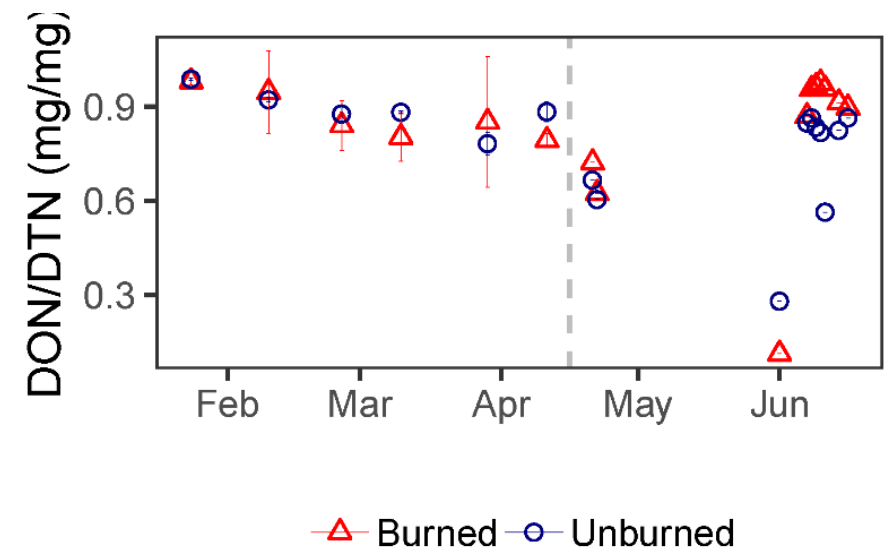

Figure S2. DON/DTN ratio in the burned (red triangles) and unburned (blue circles) watersheds. The gray dotted line indicates the date of the prescribed burn (April 16). 
Burned features- raw; binwidth $=25 ; 62.6 \%$ assigned formula

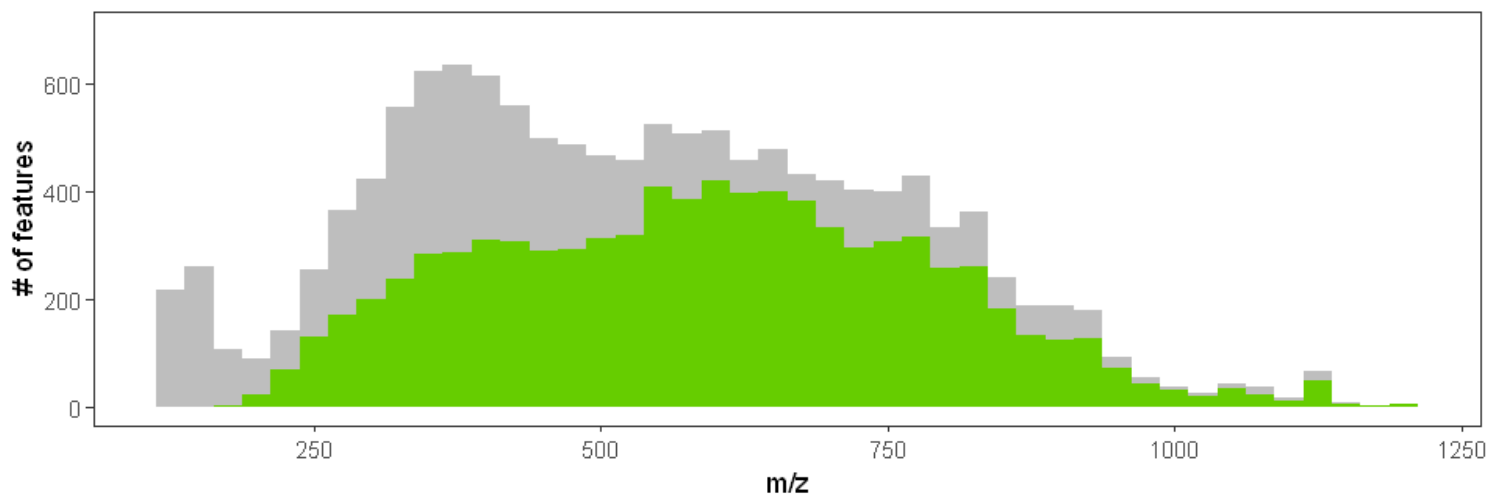

Unburned features- raw; binwidth $=25 ; 65.1 \%$ assigned formula

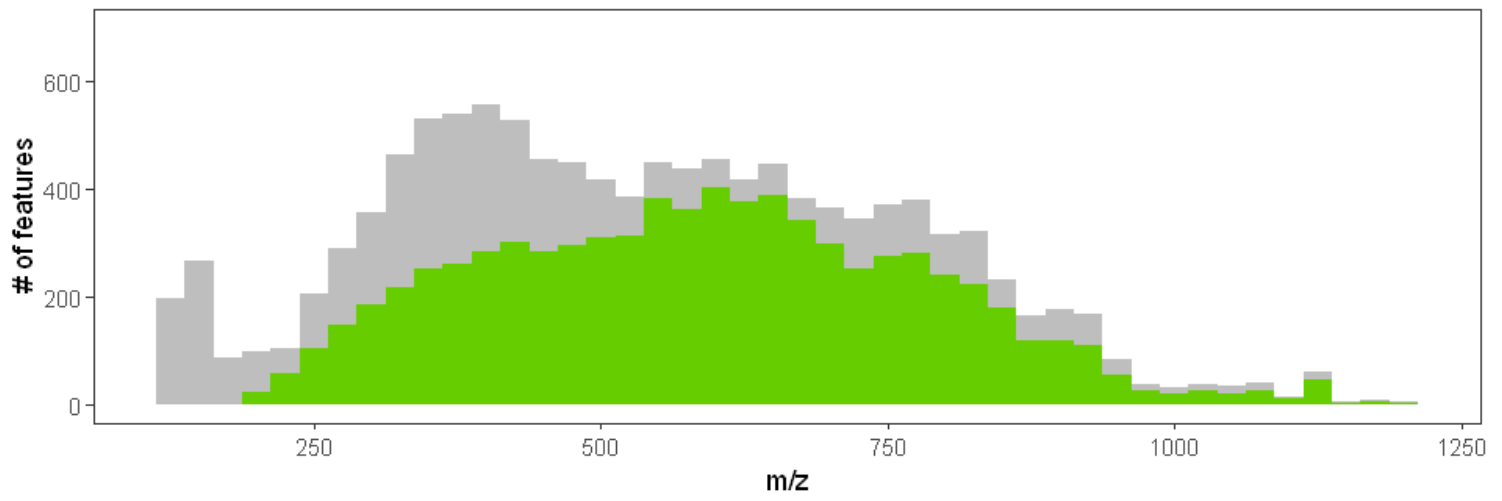

Figure S3. $\mathrm{m} / \mathrm{z}$ distribution of all features detected (gray) and features with assigned formula (green) for the Burned and Unburned watersheds 

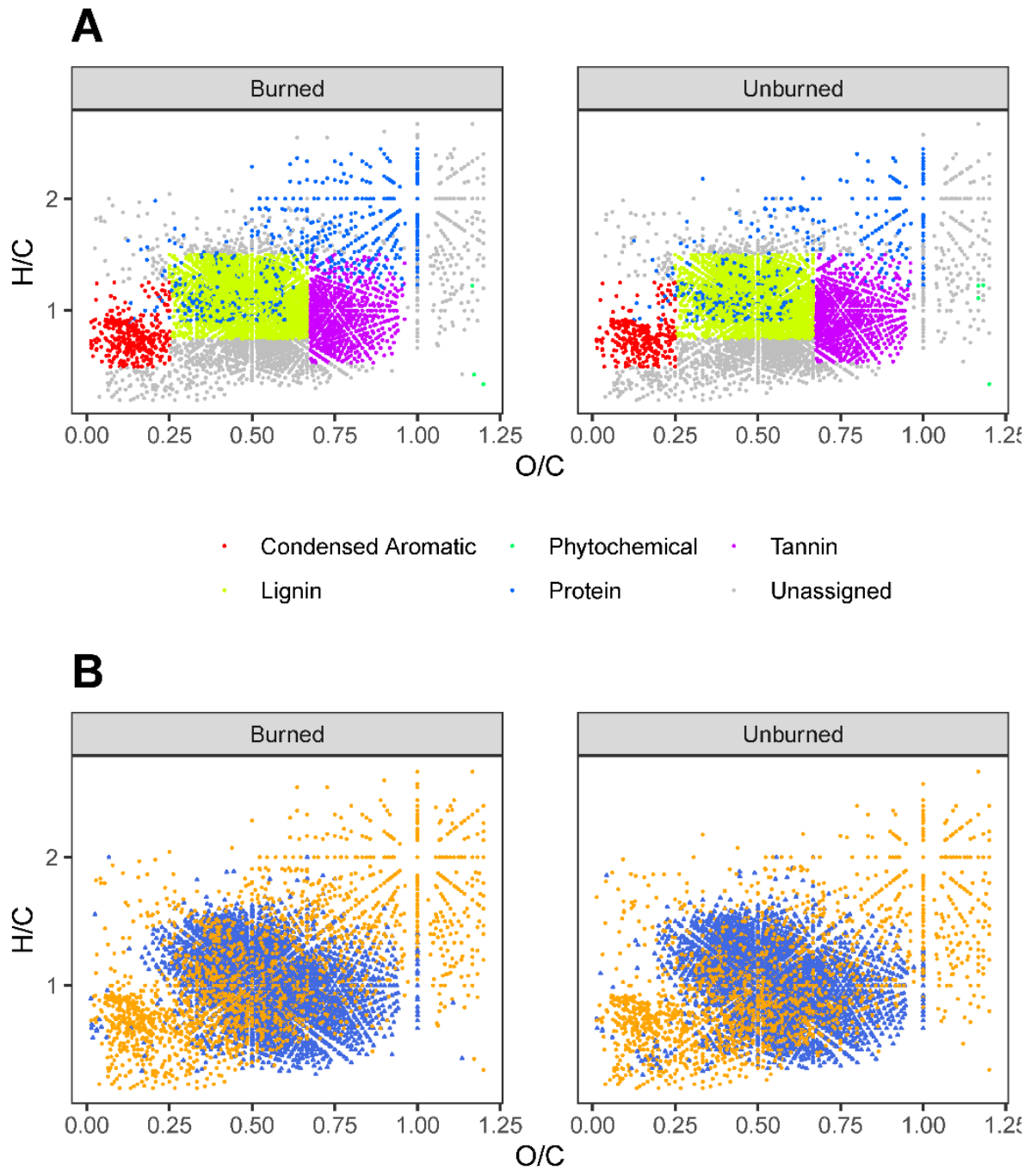

- $\mathrm{CHO}$ Heteroatom

Figure S4. Van Krevelen plots of the burned and unburned watersheds. Panel A: van Krevelen categories. Panel B: $\mathrm{CHO}$ only and heteroatom (N,P,S) containing formulas. 

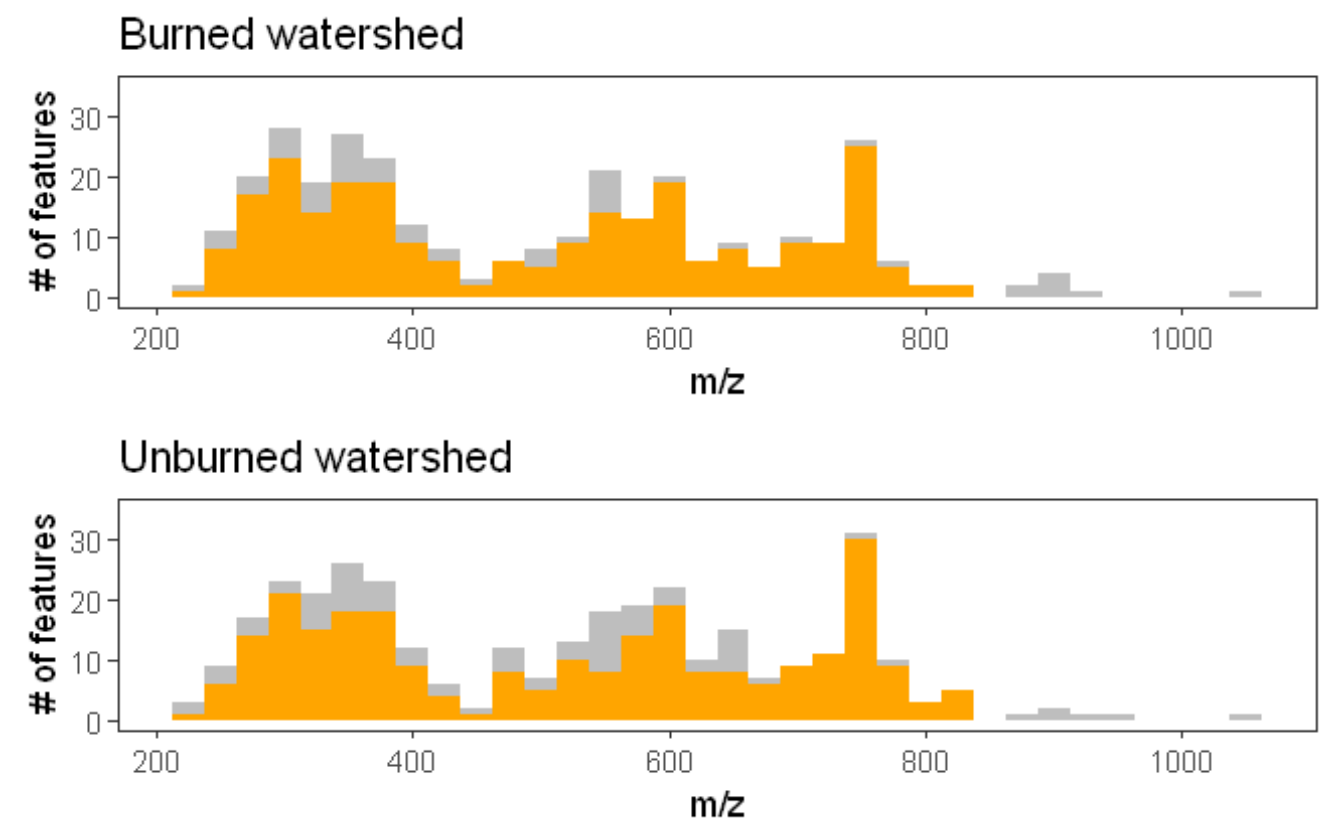

Figure S5 Polycondensed aromatic features. N-containing (orange) and all (grey) features.

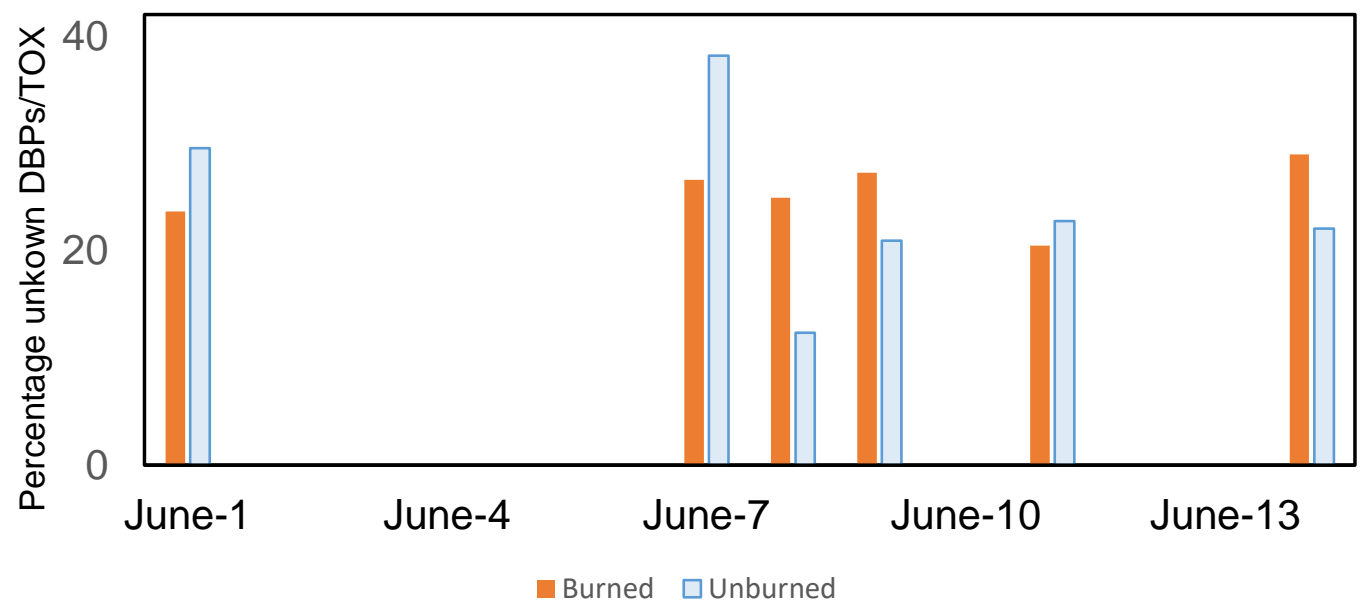

Figure S6 Percentage of total absorbable organic halides (TOX) not attributed to individual DBPs quantified in this study. 
A- Unique features in Chlorination FP test
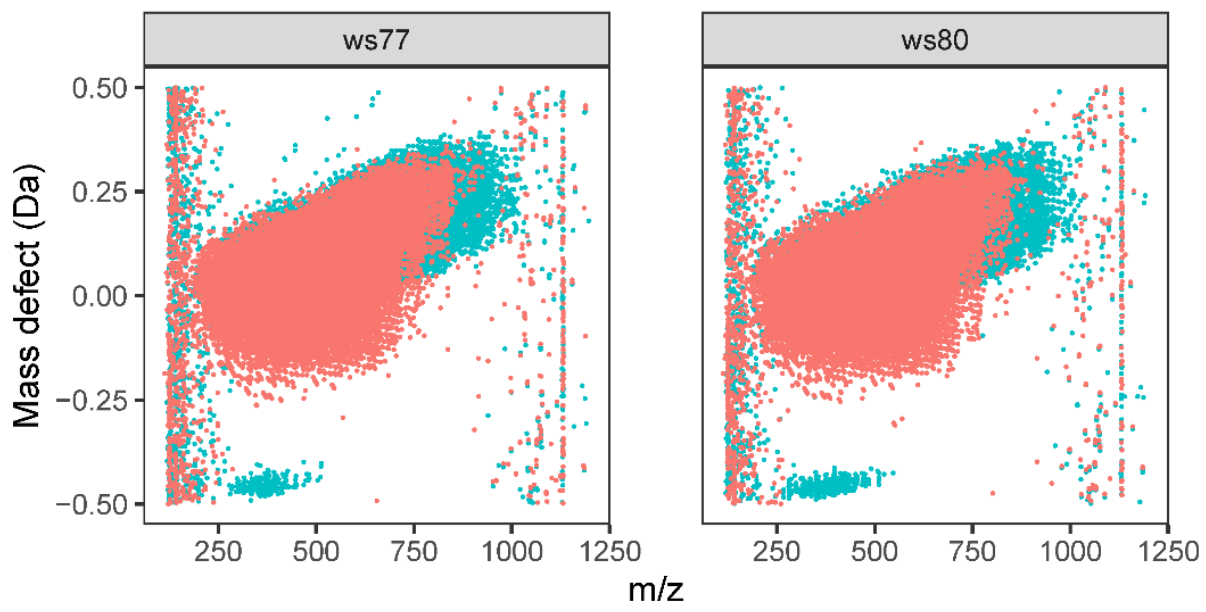

treat

$\mathrm{cl} 2$

raw
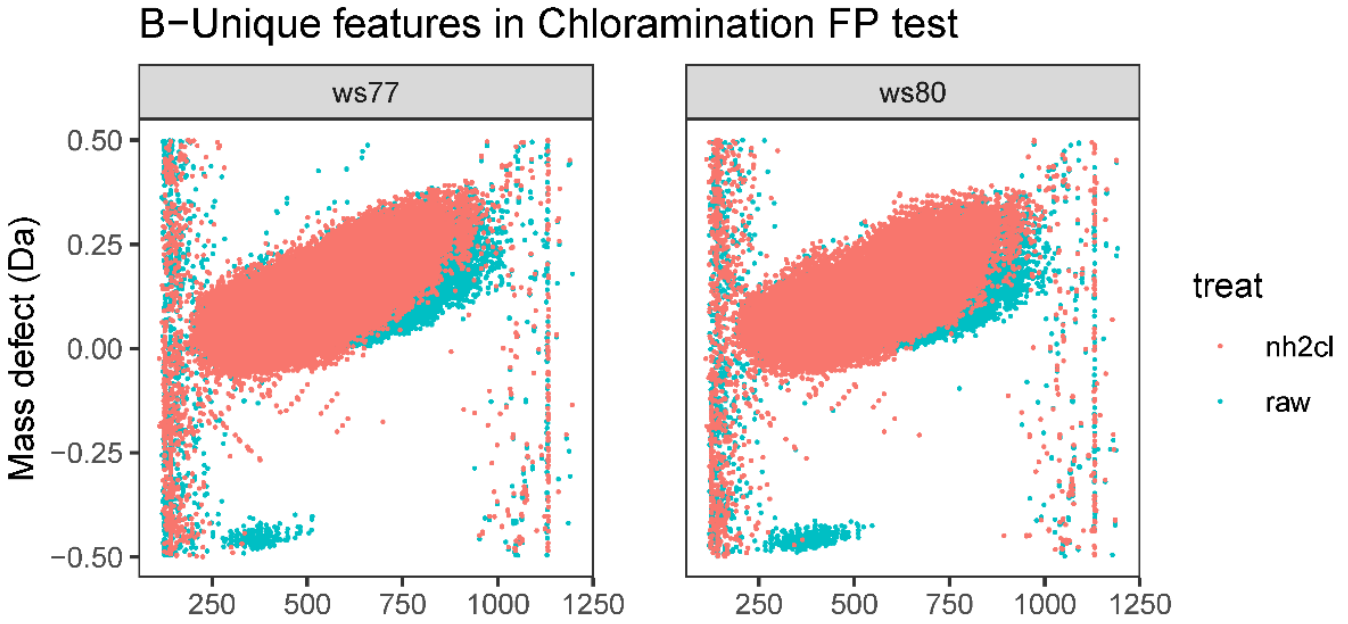

Figure S7 Mass defect comparison between raw water and chlorinated (Panel A) and chloraminated (Panel B) 